\title{
Beyond Traditional Microfinance: Financial Inclusion for Unbanked Kenyans
}

\author{
Abd Elrahman Elzahi Saaid Ali ${ }^{1}$ \\ ${ }^{1}$ Islamic Research and Training Institute, Saudi Arabia. \\ Correspondence: Abd Elrahman Elzahi Saaid Ali, Islamic Research and Training Institute, Saudi Arabia.
}

Received: June 8, 2016

Accepted: June 30, 2016

Available online: July 4, 2016

doi:10.11114/ijsss.v4i8.1715

URL: http://dx.doi.org/10.11114/ijsss.v4i8.1715

\begin{abstract}
Kenya is a leading economic country with most developed traditional microfinance when compared to its neighbourhood countries. Despite that, the country banked population rate remains stagnant at a lower level. Recently, Kenya exerts more efforts to adopt mobile money, which enables the country to achieve relatively high financial inclusion compared to before. This study investigated whether the country would be able to achieve better financial inclusion by going beyond traditional microfinance through the adoption of mobile microfinance, rather than just transferring and receiving through mobile money. Hence, the study used survey and structured questionnaires to check the readiness of the unbanked Kenyan community, microfinance providers, mobile operators, and the government for adopting effective mobile microfinance. In addition, this study also describes the benefits accrued to them. The results showed that the unbanked Kenya are engaged in microfinance enabled jobs such as self-employment and retailers. The community which was found to be highly connected with mobile phone has a lower awareness of mobile microfinance. While respondents admitted using electronic payment on limited situations, cash is still the dominated medium of making payment.Since the unbanked Kenyan are living in remote areas, mobile microfinance would help to improve their access to finance through reducing the cost of services, minimizing the physical distance to the access point, better documentation, and improving outreach by opening the untapped markets. The results of this study recommend that mobile microfinance intuitions and mobile operators need to exert joint efforts to promote more awareness and develop appropriate mobile microfinance products. On the other hand, the regulator intervention is needed to eradicate barriers such as high tariff, bad corporate governance, and dispute resolution.
\end{abstract}

Keywords: Financial Inclusion, Mobile Microfinance, unbanked community

\section{JEL Classification: G21; 010}

\section{Introduction}

Recent years has witnessed the development of modern microfinance which could be traced back to the twenty century in Latin America, India, and Bangladesh. However, Grameen Bank has been regarded as one of the most essential microfinance provider in history. Previous studies showed that most microfinance providers focus on women which made a group methodology with the primary objective of providing lending and savings products to empower micro-entrepreneurs and to create Micro Small and Medium Enterprises (MSMEs).As a job intensive tools, microfinance has become very essential for sustainable economic development. Hence, it is considered as an effective financial inclusion tool and poverty alleviator. The World Bank Report (2012) shows that poverty is widening as three quarters of the world's poor ( 2.5 billion adults) do not have a bank account due to poverty, costs, travel distances, and the often-burdensome requirements involved in opening an account ${ }^{1 .}$ Due to that, the G-20 has given financial inclusion top policy priority. Thus, it established the Global Partnership for Financial Inclusion (GPFI), which includes the World Bank, International Finance Corporation (IFC), and Consultative Group to Assist the Poor (CGAP). In addition, it also includes the alliance for Financial Inclusion and the Organization for Economic Cooperation and Development (OECD) as the designated implementing partners. Despite the world efforts to fight against poverty, financial inclusion might face more challenges for most African countries including Kenya. Just like other African countries, most of Kenya provinces, particularly East North region, face weaknesses in basic infrastructures, trade facilitation, and financial

\footnotetext{
${ }^{1}$ http://www.worldbank.org/en/news/feature/2012/04/19/three-quarters-of-the-worlds-poor-are-unbanked
} 
infrastructure development. The previous studies showed that most African countries are faced with weak basic infrastructures with remote geographical areas that made their business less competitive due to the high financing costs; hence, this is in addition to high tariffs and taxes, compared to international standards ${ }^{2}$. Moreover, the traditional microfinance involves high operational cost associated with providing financial access to a segment of the unbanked population. This segment is due to the high risk faced by most formal financial institutions in Kenya.

Hence, these challenges were fostered through the adoption of wireless microfinance. Mobile telephony has brought new possibilities to Kenya in general and North East Kenya in particular. However, it has some of the lowest levels of infrastructure investment in the country. Regardless of being poor or rich, urban or rural mobile phones connect individuals to individuals, and business to business. Thus, they are connected to information, to markets, and to services.The poor can call their relatives, locally or abroad, to seek help from them. Also, farmers can send text messages to request information about the condition of the market and crop prices. If the wireless connectivity is well utilized, it might lead to tangible economic benefits. These benefits could be the improvement in the life of low income and unbanked population. Thus, this leads to reduction in unemployment and the promotion of economic growth. Since mobile devices enable people to withdraw cash, transfer money, apply for loans and check account balances, it is strategically valuable to the unbanked population. These unbanked populations comprises of the poor and low-income households that live in remote areas. Consequently, they have less physical financial intuitions coverage to have access to the mainstream financial system.Therefore, this research is intended to inform the policy makers, financial institutions, and entrepreneurships that the adoption of mobile microfinance in Kenya may create a great deal of hope regarding its effect on the economic development of the poorest areas in the country.

\section{The Status of Microfinance in Kenya}

Kenya is the leading economy in the East Africa region, and serves as the regional business, transportation, communication, and financial hub ${ }^{3}$. It has relatively developed financial infrastructure with commercial banks, very vibrant rural-based savings, and credit co-operatives compared to its surrounding region. Moreover, Kenya has most of the advanced conventional microfinance sector in the region. Despite that, the usage of microfinance services in Kenya has remained stagnant at $3.5 \%$ of the total "banked" population in the period between 2009 and $2013^{4}$. Therefore, this stagnation was due to the low savings rate, isolated areas, and far distances to the point of service. This is in addition to the poor governance at the public and private sectors level. It is also worthy to note that Kenya's $43^{5}$ licensed banks are far below sufficient for its 43.35 million $^{6}$ population. Despite the recent development of branchless banking (M. Banking) that has helped the unbanked people reside far away from the physical bank branches, mobile money has already started in Kenya. According to the Global 2012 Global Mobile Money Adoption Survey ${ }^{7}$, Kenya's accounts, among the African countries that have more mobile money, was compared to the regular bank accounts. This wireless infrastructure if properly used could easily help unbanked Kenyaian in accessing financial services through their mobile phone to transform the existing conventional microfinance into more reachable mobile microfinance. Given the remote areas, mobile microfinance might be among the best tools that enables the effective financial inclusion for the unbanked rural areas people. Despite the advance adoption of branchless banking in Kenya, more people particularly in North East Kenyan were almost excluded from access to fianances. Furthermore, the recent establishment of mobile microfinance institutions such asMusoni BV is very promising. Musoni BV is a $100 \%$ mobile microfinance institution in the World ${ }^{8}$. It is important to note that the government is in the midst of operationalizing its Financial Sector Medium Term Plan ((MTP) 2012-2017). Therefore, it was developed to pursue the objectives of Kenya's Vision 2030 policy. This plan sets out sector priority goals that include the enhancement of financial inclusion through widening access to affordable financial services and products to a majority of the Kenyan population especially the unbanked communities. Hence, given the increasing number of the Kenyans who have access to a mobile phone, people, at least in the urban area, are currently adapting to the use of mobile money transfer services. In Kenya, the government has shown positive efforts in encouraging branchless banking. In addition, the introduction of mobile microfianance could help more in the financial inclusion of the unbanked Kenyans.

This study has covered six locations within Nairobi County.First is Gikomba- The worlds' largest second hand market which hosts more microfinance intuitions (MFIs) such as Faulu Kenya, Century \&Rafiki Deposit Taking Microfinance Ltd. Second county is the Kibera-Thesecond largest slum in Africa, which is home to 700,000 -1,000,000 Kenyans

\footnotetext{
2 The challengesof Islamic Trade Finance in Promoting SMEs in IDB Member Countries

$3 \mathrm{http}: / /$ www.iesingapore.gov.sg/Venture-Overseas/Browse-By-Market/Africa-Middle-East/Kenya/Country-Information

${ }^{4}$ FinAccess report 2013

5 Central Bank of Kenya -Website

6 World Bank Kenya Data

$7 \mathrm{http}: / /$ www.aboutmicrofinance.com/reaching-the-unbanked-mobile-banking-and-microfinance

8 http://musoni.eu/about-us/
} 
housing M-Changa SMS-based crowd funding app that offers users the abilityto target domestic donors versus the international donor community. Thirdly is Zimmerman - Hosting Musoni BV which had 10,600 clients with a loan portfolio of EUR 2.2 million $^{9}$ as at May 2014. The fourth location is the Kawangware -Home which has invested over USD10 million aimed at bringing financial services closer to the marginalized. Thus, this is achieved by using technology to overcome barriers such as illiteracy, expensive transportation, and geographic isolation. The fifth location is the Githurai-Mixture of slums and suburbs where insecurity is quite high leading to a preference for dealing with mobile money. The six and final area is the Embakasi - entrepreneurs are benefiting from Kiva Zip. However, Kiva Zip is a pilot program launched by Kiva, the world's first and largest micro-lending website that is leveraging on MPESA. The main objective of this study is to determine whether unbanked Kenyans benefit from moving beyond traditional microfinance to mobile microfinance. More specifically, the study examines the readiness of the unbanked Kenyan community, microfinance providers, mobile operators, and the government for adopting effective mobile microfinance. Finally, the study explores how mobile microfinance providers had better serve the unbanked segment.

\section{Literature Review and Methodology}

A bundle of literatures is available on mobile and branchless microfinance. Eisenmann et al. (2009) carried out a study on the users of mobile banking. It shows that mobile users who are young are easier to adopt mobile banking than older users since they value time and often considers it to be more convenient than older users. Moreover, the younger users learn how to use mobile application faster than the older age. Njenga (2009) investigated the mobile phone banking usage experiences in Kenya. He found multiple outlets available across the country, which might imply more points of contact with customers as opposed to the traditional banking hall set up. He also found that the flexible operating hours of the M.Banking agents leaves clients with greater opportunities to satisfy banking requirements that may arise at any time. This is a significant indication of the high value level on the convenience associated with the use of the mobile payment services. Another study conducted by Omwansa (2009) in Kenya found that a lost or stolen mobile phone does not mean catastrophe because no one can access an M-Pesa account without a correct personal identification number (PIN). He further found safety which represents no delay, no transaction incompleteness, and no private information disclosure during payment transactions. Mobile banking includes confidentiality, authentication, data integrity, and non-repudiation (Omwansa, 2009). According to the finAccess report of 2013, 32.7\% of the adult population accessed financial services from the formal. There has been an increase in formal prudential financial inclusion of $10.6 \%$ from 2009 to 2013 compared with a 7.1\% increase between 2006 and 2009. The decrease in the proportion of people excluded between 2009 and 2013 was $6.0 \%$ compared with a $7.9 \%$ decrease between 2006 and 2009. The proportion of people relying solely on informal types of financial services has been steadily decreasing.

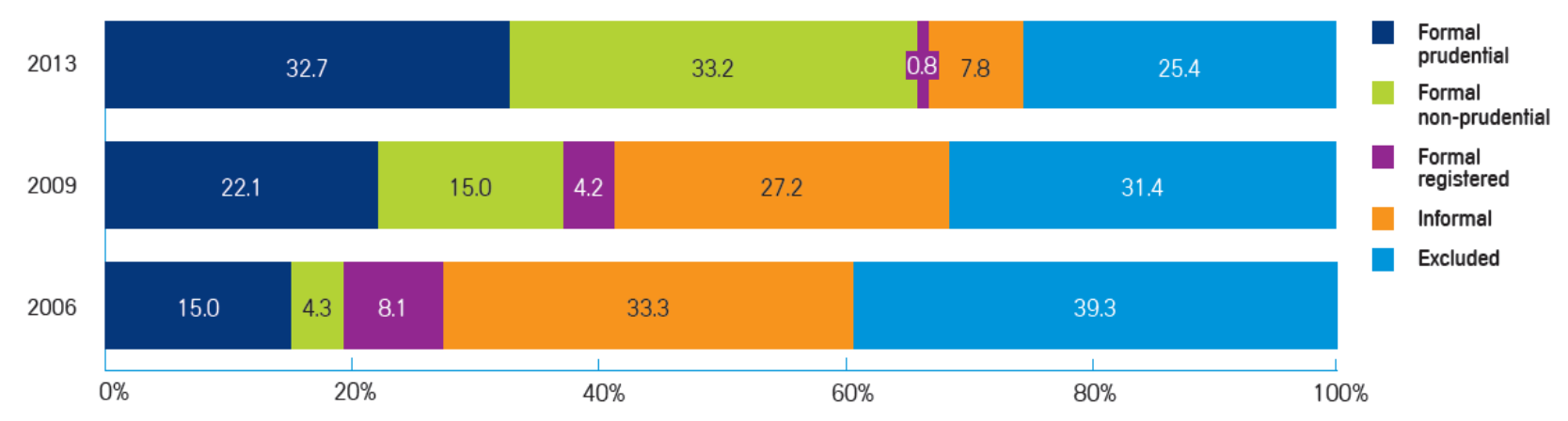

Figure1. Access Strands by year (Source FinAccess report 2013)

Daniel (1999) found more dissatisfied consumers with the traditional services which were switched to electronic mobile services. Thus, branchless finance might overcome the challenges of competent staff availability, inconvenient branch opening hours, and the speed at which they received services at the bank premises. Black et al. (2002) notes that those consumers who adopted mobile bank services early and who utilize the online banking heavily, are more satisfied than the later adopters. In addition, literature established that there was preference by consumers for service delivery through multi-channels than through single channel (Merwe, 2001). This calls for mobile microfinance providers to improve all channels rather than isolate some and concentrate on only one of them. Moreover, Zift (2006) found that many mobile phones users are not aware of the existence of mobile banking services which are being offered by MFIs. In addition to that, others found online bank sites as being complex. As a result, they become reluctant to take advantage of mobile banking services. Daniel (1999) investigated a model of trust for consumers who are in India where he found the

\footnotetext{
${ }^{9}$ http://rsr.akvo.org/project/2163/
} 
antecedents of trust being 'opportunistic behavior', 'communication', and 'shared values'. Subsequently, the last two is quite significant and important as they influence consumers trust and commitment. Therefore, the above literatures which show considerable research have been carried out on mobile banking, mobile money, and wireless MFIs. However, a clear picture of the relationship between these, the benefits accruing to the unbanked population, and the challenges faced, have not been investigated at least in Kenya. The existing body of knowledge is thus not sufficient to explain the benefits of mobile financial services on the unbanked Kenya. Therefore, this represents the gap intended to be filled by this research.

This study used a survey to collect data to answer main questions such as; do the un-banked Kenyans benefit from adopting mobile microfinance and how can mobile microfinance providers better serve this important market segment? The survey team approached 600 individuals selected randomly from the urban and pre-urban areas of Gikomba, Kibera, Zimmerman, Embakasi, Kawangware, and Githurai of Nairobi. The sample covers individuals and the large pool of informal single-person businesses that dominate the landscape in most of these locations. Quality responses were received from 596 individuals.A structured questionnaire and one Focus Group Discussion (FGD) were carried out to collect quantitative data and qualitative data, respectively. Details pertaining to the participants of the survey were presented and were given upon request. Twelve enumerators who speak local languages and are familiar with the different localities were hired to administer the survey over a period of 5 days. One-day training session for enumerators, to help them understand the objectives of the research study and learn how to administer the questionnaires, was undertaken. Respondents were asked a set of screening questions such as whether or not they own a mobile phone and/or perform microfinance transactions on them. They were also asked if they make use of other alternatives and the reasons why they do/do not have access to such services. The next set of questions determined payment behavior, financial literacy, and awareness. This was followed by questions on the complexity of the user's interface, attitudes, and perceptions. The final set of questions sought to determine the actual benefits accruing to the unbanked and their demands for future mobile microfinance services and products. The completed questionnaires were checked every day at the time of collection from enumerators for: a) completion of the questionnaires, b) confirmation that all the questions were asked and properly completed, c) adherence to the skip patterns, d) symmetry in the data collected for each questionnaire. When the paper-based forms were not completed as expected, clarification from enumerators was sought. Data was then captured and analyzed using SPSS.

\section{Results and Discussions}

Given the poor basic infrastructures such as road, electricity and the far distances between the rural and urban cities in Kenya, the adoption of branchless microfinance might be of great benefit for the poor rural community of Kenya.In terms of demographics, the highest reported age on this survey was ranged between 26 and 45 years old. Hence, this is quite appropriate considering that this age group will find it quite easy to adopt mobile microfinance. Concerning marital status, $49.45 \%$ of the respondents reported being married. On the other hand, $43.77 \%$ of the respondents were single. Since the literacy is significantly important for the branchless microfinance dealers, $39.19 \%, 37.55 \%$ and $16.30 \%$ of the respondents reported having attained secondary school, technical college and university level education, respectively (Figure 2). Therefore, this was relatively a literate sample considering Kenya's literacy rate of $87.01 \%$ according to the World Bank report in 2009. The degree of high literacy in Kenya might imply one of the positive sign for the success of the mobile microfinance.

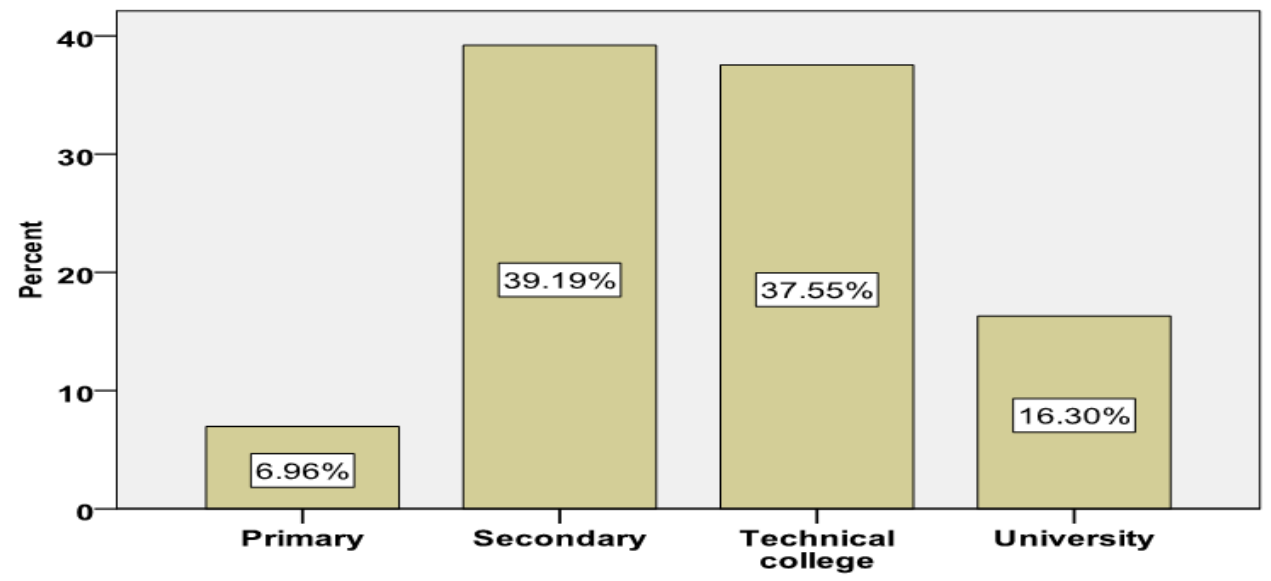

Figure 2. Respondents Level of education

Concerning the occupation, the family owned/self-employed and employment in private business dominated more than 
the occupations. Figure 3 showed that $41.25 \%$ and $30.20 \%$ of the respondents are self-employed and are private business employees respectively. However, only $3.87 \%$ of the respondents classified themselves as working for the government and $11.23 \%$ were classified as students.

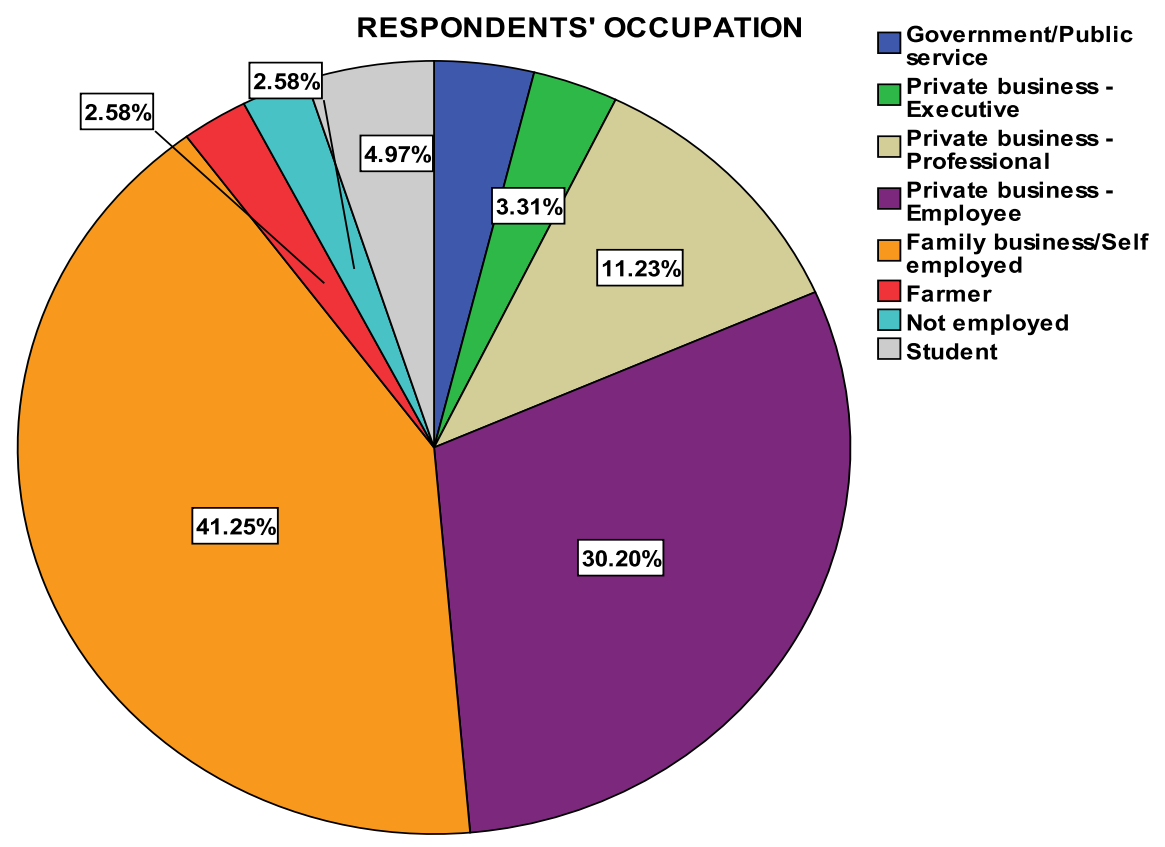

Figure 3. Respondents Occupation

The study investigated the average income. Therefore, the majority of the respondents reported that they earn low income. The results indicate that $55.79 \%$ were employed in small business (Figure 3), while $71.24 \%$ respondents reported an average monthly income of less than KES 20,000 (\$235) (Figure 4).Thus, the investigated sample is biased toward low-income services, small business, and retail jobs. Hence, this is typical of the locations studied. Moreover, these types of occupations represent suitable clients for mobile microfinance in Kenya.

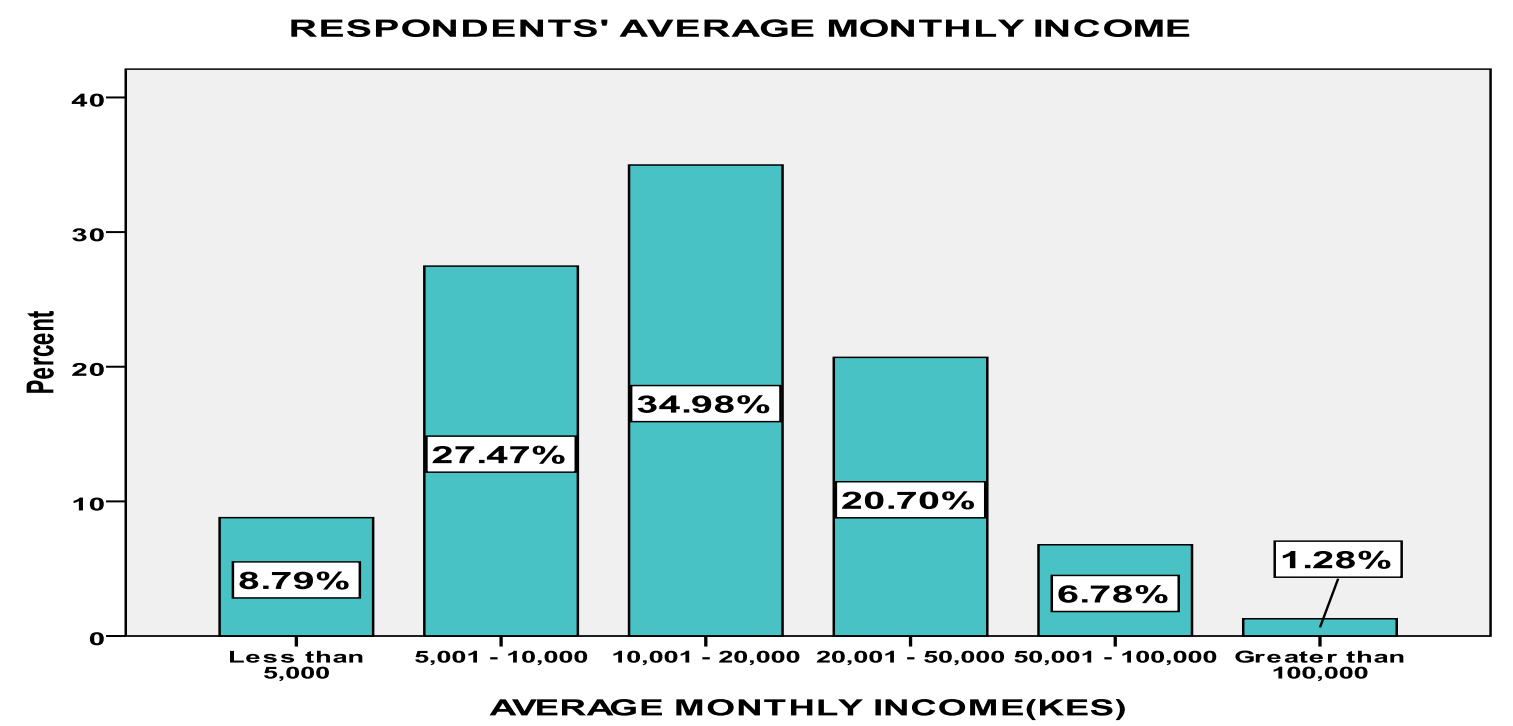

Figure 4. Average monthly income

In order to adopt mobile microfinance effectively, the awareness of the targeting groups are very important.In this, regard, $46.55 \%$ respondents rated their knowledge related to the mobile microfinance as low, while only 1.7 of the respondents were highly aware of the wireless microfinance (Figure 4). When the respondent asked about which types of media they mostly use in generating knowledge about microfinance, $88.33 \%$ reported the mass media such as the radio, T.V, and the newspapers. While they gain awareness, only $5 \%$ were reported through family and friends (Figure 6). Hence, illiteracy about mobile microfinance represents one of the most challenges facing branchless financial institutions in Kenya to go beyond traditional microfinance. Therefore, these results suggest that mobile microfinance 
providers might need to exert additional efforts to promote more awareness of mobile microfinance knowledge among the unbanked Kenya. Moreover, mass media is likely to represent the right and the effective method of raising the awareness of wireless finance for all the targeting categories of respondents. More preferably, it uses local languages or Kiswahili if requisite knowledge benchmarks are to be attained.

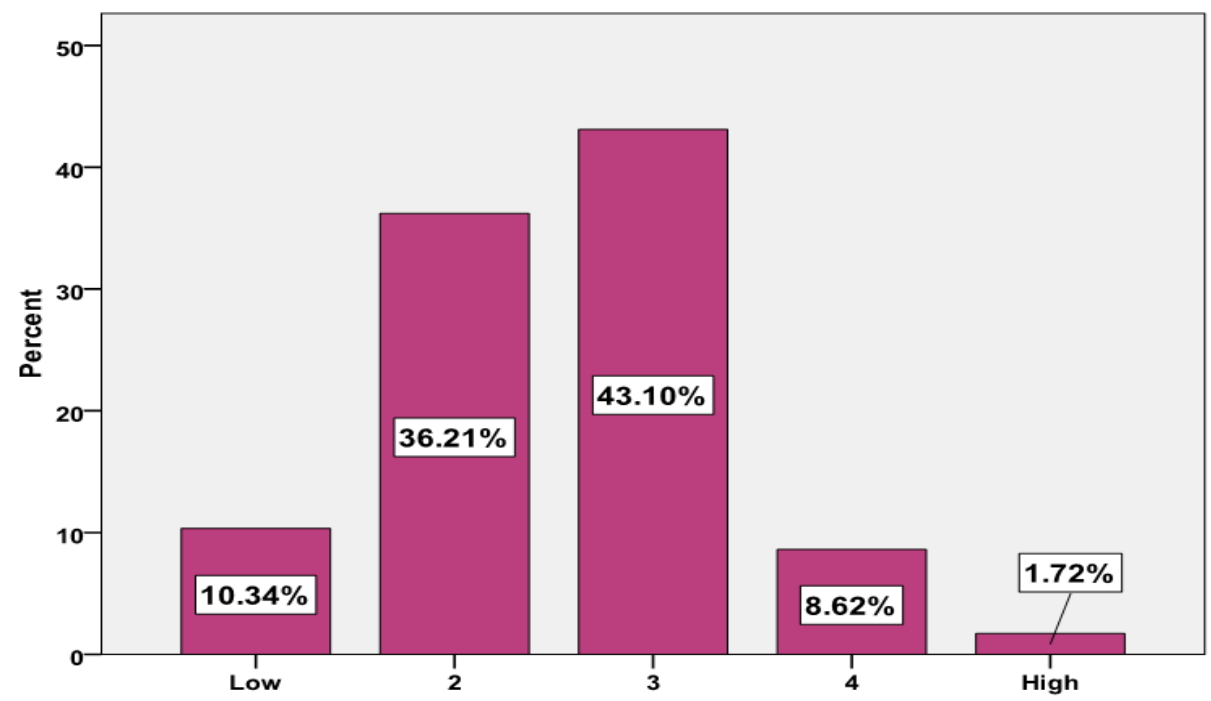

Figure 5. Respondents knowledge of Mobile Microfinance Services

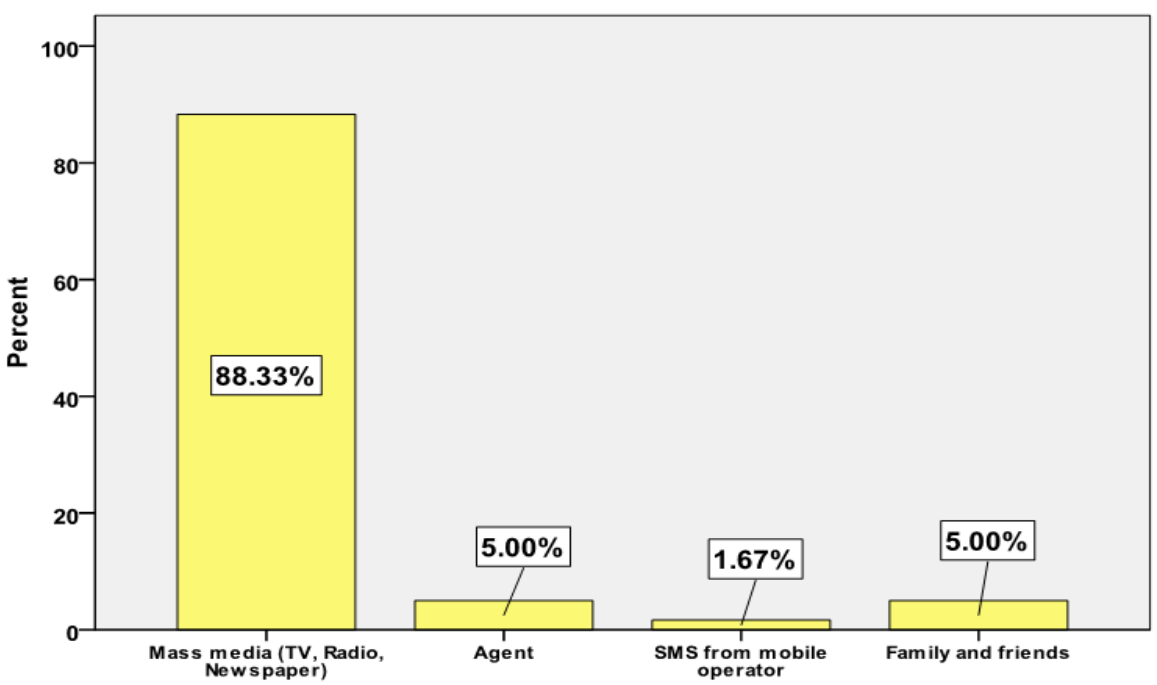

Figure 6. Where did you hear about mobile microfinance services?

In order to promote mobile finance among the unbanked community, the branchless institutions assumed that these people are connected to their wireless devices. This study has investigated connectivity, which shows that all the individuals in the sample were highly connected. $93.1 \%$ of the individuals responded that they own a mobile phone, compared to the Nairobi's average of 88.3 percent10. Based on the ability to use different devices such as mobile phone, ATM Machine, Internet, Point of Sale and Debit Card, mobile phone was ranked to be very high. Thus, this is followed by ATM and Debit Card. These facts highlight the opportunity for mobile microfinance institutions to reach the un-banked populace so long as they properly designed mobile enabled products and services and conduct thorough awareness.Most of the respondents claim that they are aware of how to use the wireless devices. As far as user friendliness of the mobile microfinance menu was concerned, $74.34 \%$ of the respondents indicated that it was easy to use. More than $69 \%$ reported that they did not find any difficulties to navigate. Considering the weakness of the basic infrastructures and the cost of transportation and the distance between the physical banks, there is a claim that the wireless microfinance might be cheaper than the traditional microfinance. This is very clear from the answer of the

10 The Daily Nation - 10th Nov 2014 
question whether mobile microfinance is cheaper than traditional microfinance. Furthermore, $81.15 \%$ of the respondents indicated that it was cheaper compared to $18.85 \%$ who indicated that it was not (Figure 7). This result might motivate the mobile microfinance providers to place more investment to promote their wireless services among the unbanked community in Kenya. This is because the cost of accessing financing was found to be a major factor to achieve financial inclusion among the poorest community.

\section{RESPONDENTS' VIEW ON MOBILE MICROFINANCE SERVICES BEING
CHEAPER THAN TRADITIONAL MICROFINANCE SERVICES}

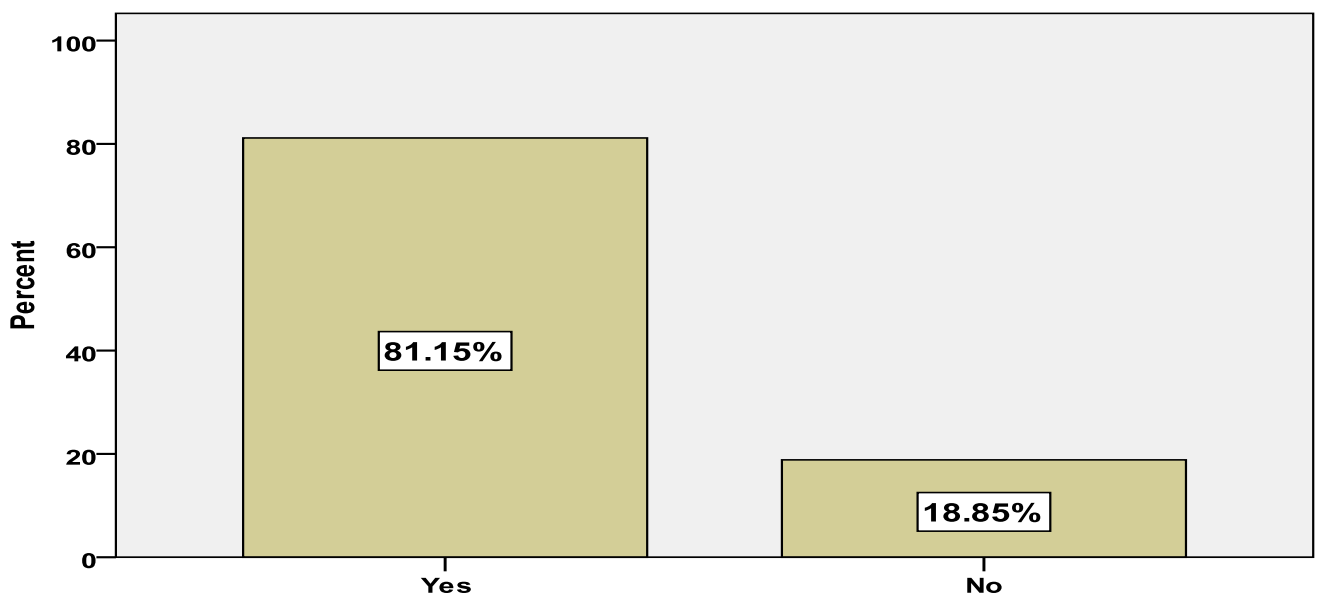

Figure 7. M. Microfinance Cheaper than Traditional Microfinance

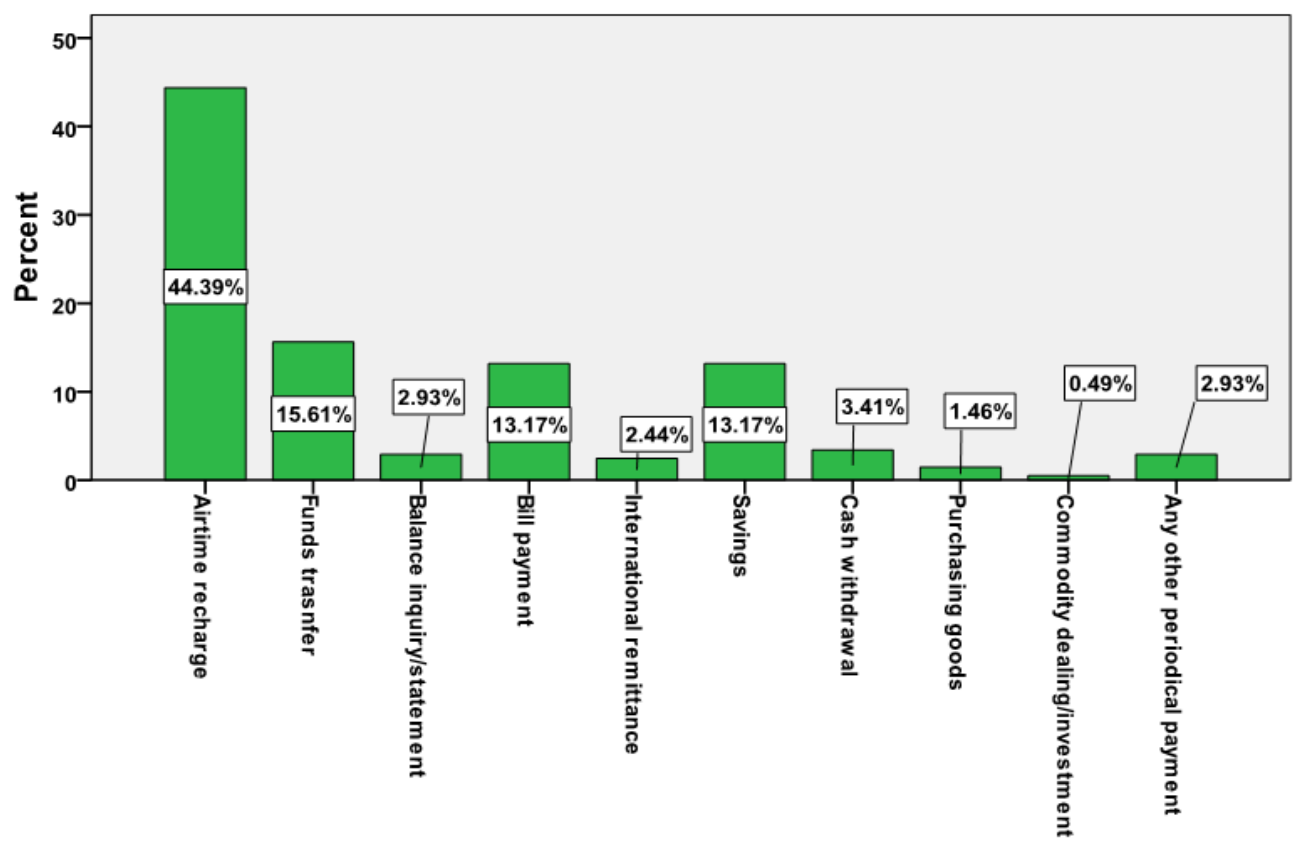

TRANSACTION

Figure 8. Mobile Microfinance Transactions

The study has also investigated the possible transactions that unbanked community might use for their mobile devices. The savings, airtime recharge, bills payment, funds transfer, and balance inquiry are among the most popular transactions surveyed. The results indicated that many individuals reported the intensive use of mobile microfinance. Saving, fund transfer, and the airtime recharge $(44.39 \%)$ are carried out among the most popular transactions. Figure 8 reported that $13.17 \%$ of the respondents indicated that they use Mobile Microfinance for savings, while $15.61 \%$ of the investigated sample indicated that they used it for funds transfer. However, this implies that the mobile microfinance providers might exert less effort to transform these unbanked people to consume their products. Since the social bonds among the unbanked community is very strong in Kenya as it exist generally in Africa, most respondents indicated that 
prompting from friends, convenience, and safety are among the paramount reasons for choosing mobile fund transfer. As a result, it might make mobile microfinance to be conducted easier among them over the traditional method. Hence, the fact individuals value the ability to transact through mobile and prompt each other to take up the wireless service could virally spread the supply chain in Kenya. Mobile microfinance operators, therefore, have an opportunity of tapping into the viral adoption cycle. Also, the unbanked population which uses mobile microfinance should come as no surprise. This is because this populace, just like any other one, does have a need to save, take up loans, and pay and receive funds frequently. Sometimes, it is carried out over long distances.

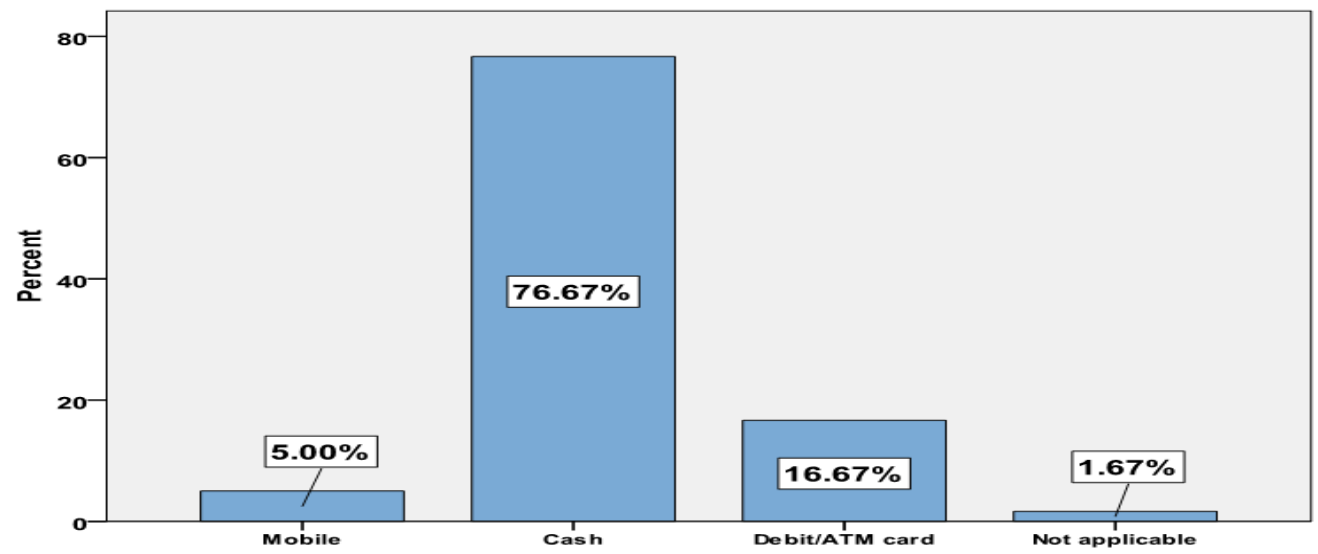

Figure 9. Methods of Payment

Concerning the popular methods of payment, the survey indicated that cash payment $(76.67 \%)$ is still the most used among the unbanked Kenyan, particularly for paying periodical payments such as school fees. Additionally, rent and purchase of consumables for the home are areas where cash still dominates all other forms of payments (Figure 9). The high frequency usage of cash might indicate that mobile microfinance has some way to go in replacing cash that is used quite significantly in the Kenyan economy. Moreover, mobile microfinance has made significant progress, especially in the areas of paying suppliers and paying bills: These two areas which were counterparties are more sophisticated. Hence, they require mobile money payments.

The study attempt to find which institutions is providing mobile microfinance more in Kenya. It aims to check whether microfinance intuitions or mobile company operators are the major provider of microfinance. The results reveal that microfinance institutions ranked slightly lower compared to the mobile operators in providing mobile microfinance. On the other hand, they do better if they worked in joined efforts. This is clearly depicted in Figure 10 which indicated that microfinance institutions were ranked third by $16.73 \%$ of the respondents, while the mobile operators were $20.82 \%$ in term of providing mobile microfinance services and products. Curiously, evidence points to the fact that joint operations between mobile operators and microfinance institutions were ranked the highest at $59.48 \%$. Hence, in order to achieve the intended financial inclusion among the unbanked Kenyan, a collaboration between the two different institutions needs to be enhanced. 


\section{PROVIDERS OF MOBILE MICROFINANCE SERVICES}

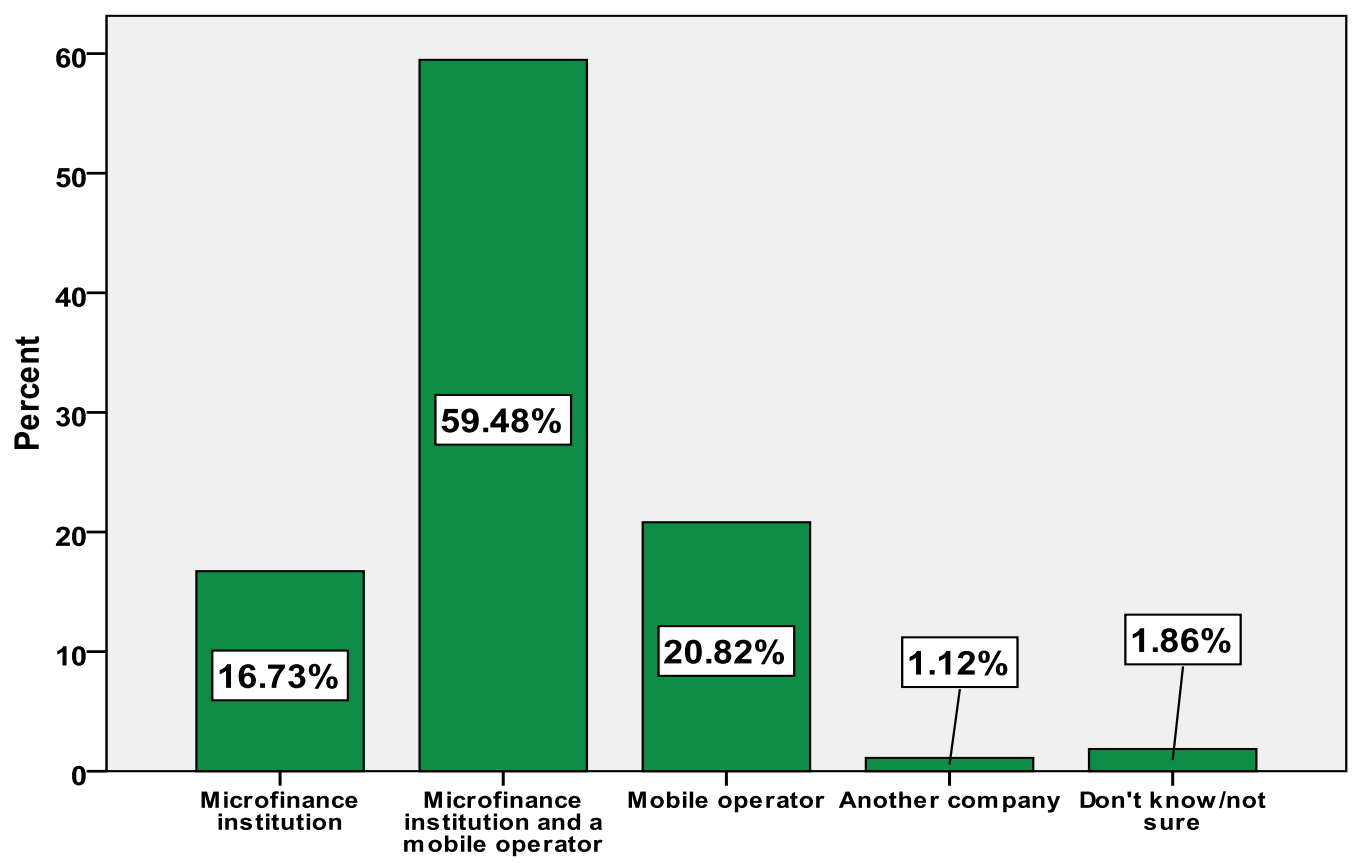

Figure 10.The Providers of Mobile Microfinance

When asked about the benefits of using mobile microfinance, $79.68 \%$ of the respondents cited security followed by better accountability, as well as the fact that the receipt of SMS leaves an audit trail. Moreover, the lower cost mobile microfinance, time saving, and 24/7 access to financial services are another benefits that were also ranked highly by the respondents. In fact, $48.92 \%$ of the respondents reported accessing mobile microfinance services outside the banking business hours of the traditional microfinance institutions. However, this indicates a very convenient service. In addition, it gives more flexible time. Moreover, the small and single business owner has reported that mobile microfinance is useful for keeping the record contrary to the period prior when they were not able to keep any 'formal' records. This means that the electronic record associated with mobile microfinance transactions presents a unique opportunity that attract single business. This might assist them in understanding the implications of reducing the cost of mental and/or paper based record keeping. Despite the positive perceptions of the individual and single business owners about wireless microfinance, still, there are more impediments, which might need to be mitigated for the success of this unconventional microfinance. Although $81.15 \%$ of the respondents stated that mobile microfinance are cheaper than the traditional microfinances, tariffs, lack of awareness, mistrust, and the complexity of user interface represents part of the obstacles that might hinder the current mobile microfinance progress. Like other African country, the existing tariff structure might need to be restructured to be compatible with most common transactions-the small and frequent mobile type of payments. Other challenge, which might be experienced by the users of mobile microfinance, is the illiteracy of the users concerning wireless technology. The study found that $25.65 \%$ of the respondents claimed that mobile microfinance user's interface is not easy, while $21.36 \%$ indicate that it was difficult to effect transfers. Moreover, $40.32 \%$ cited the challenge of the complexity issues and $40.11 \%$ in checking loan balances and loan applications. In addition to that, more mobile customers are complaining about the capability of some mobile microfinance providers in Kenya in providing convenient mobile services. They have only a limited users interface services and, in some cases, lack of record management functionality. Therefore, while many single business owners did report on relying on their SMS history as a crude form of electronic record-keeping, its lack of functionality can somewhat be a barrier to the adoption of mobile microfinance. 


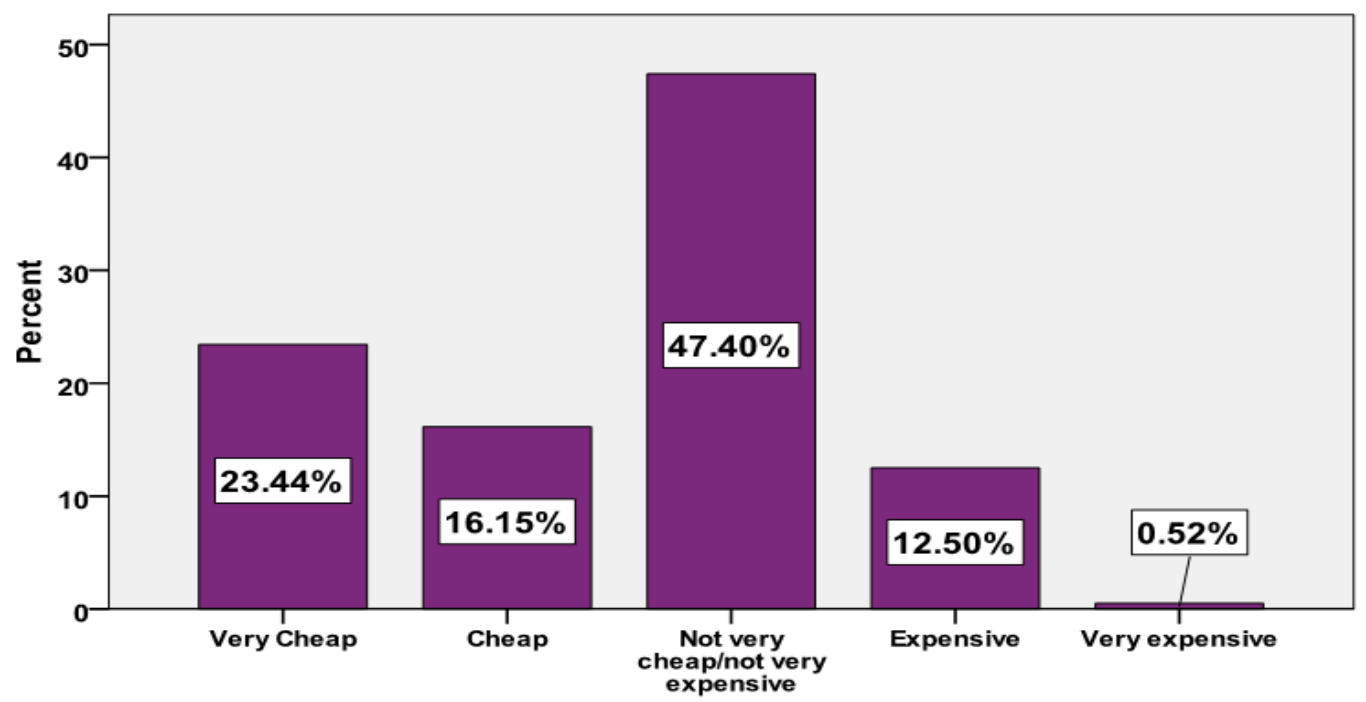

Figure11. Respondents Perception of Mobile Microfinance Tariffs

The study reveals the distance of the mobile microfinance. Therefore, the users does not represent a big barrier. Hence, only $20.07 \%$ respondents indicate that mobile microfinance is located more than $1 \mathrm{~km}$ away from where they live (Figure 12). This was, however, not cited as a major source of concern since it did not prevent the unbanked Kenyan from accessing mobile microfinance services and products. Instead, it shows how successfully mobile microfinance is blanketing the Kenyan landscape.

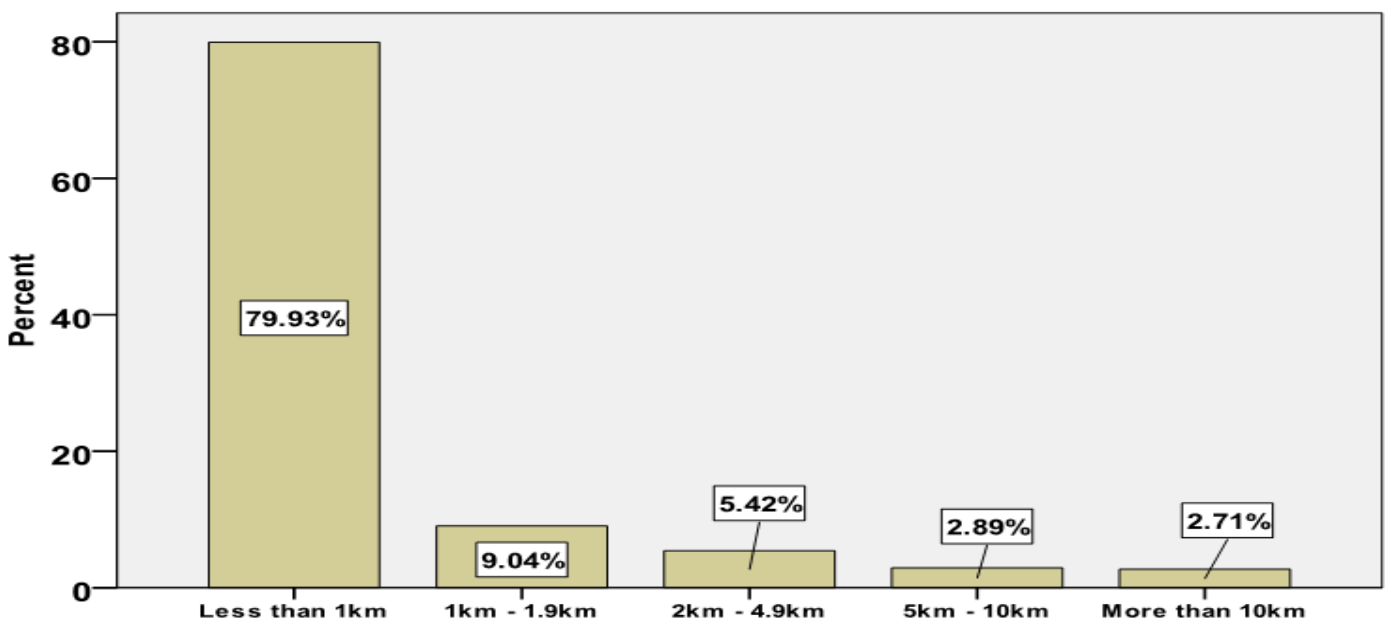

Figure 12. How far is the microfinance branch from where you do business or live?

The study has investigated the reasons that might have motivated the unbanked Kenyan to get involved in mobile microfinance. The respondents cited many reasons, such as reducing the tariffs, reasonable mobile microfinance location, and solving the security issues. The majority of them cited that they might be motivated by lowering transaction costs. On the other hand, others have indicated that the prompt feedback mechanisms are very important. In addition to that, $74.60 \%$ were concerned about the physical security, $91.01 \%$ stated security from fraud, and $62.43 \%$ indicated more locations for cashing out money. Therefore, these are reasons that would entice them to take up mobile microfinance services. When asked about the kind of mobile microfinance services, the respondents would want to see it being offered in the future. However, they ask for more wireless products such bill payment options, salary deposit, pension fund management, and investment. Based on this, mobile microfinance providers therefore need to understand the unique needs of the unbanked Kenyan who tend to be intensive users. This is in terms of the number of transactions and the number of counterparties despite the small volumes that are involved. The findings therefore indicate that a significant step that would drive adoption to improve the content of the transactions were recorded by including the source and purpose of payment. It is also done to improve access to the record in the form of an online or SMS based interface. The findings also indicate the need for a set of other features that would motivate adoption mobile 
microfinance such as the ability to manage the reversal of transactions and the reduction of fees that is so far below traditional microfinance rates and flexible/speedy responses from the mobile microfinance service providers. Perhaps, more than anything, single business owners needs to be offered a platform to change their perspective on mobile microfinance. Similarly, businesses will be able to use their electronic value to pay their suppliers and employees by avoiding the need to deliver cash payments in person. Consequently, this way of wireless payments might assist the business to manage and track all the parties and the transactions more efficiently through wiring payment value chain. Hence, in achieving this purpose, mobile microfinance providers need to keep a close eye on cost and convenience while focusing on developing in-house tools and products. This is done through partnerships with mobile network operators to offer the unbanked poor people in Kenya an appropriate solution which are financially inclusive and profitable.

\section{Conclusion}

Despite the availability of the poorest unbanked community in some Kenyan provinces, particularly in the East North of the country, Kenya is a leading economy country in East Africa with relatively financial infrastructures.Recently, the country exerts more efforts to adopt mobile money. This enables the country to achieve high financial inclusion worldwide that would reach its unbanked population living in the remote areas. Although, Kenya has most developed traditional microfinance when compared to its neighbourhood countries, the banked population rate still remains stagnant at lower level due to the low saving and the existence of the unbanked population in the remote areas. Hence, the transformation of the existence of mobile money into a more effective mobile microfinance would better help in improving the current situation of the financial inclusion. Mobile microfinance could reach to the deeper and remote areas where the unbanked Kenyan was with less cost. This study investigated whether the unbanked Kenyan would benefit from going beyond traditional microfinance through the country's adoption of accurate mobile microfinance beyond just transferring and receiving the money. The study also attempt to find if mobile microfinance is found to be more effective for financial inclusion in Kenya, and what are the challenges that might be faced and that needs to be mitigated.

Using survey and structured questionnaires, the study investigates the readiness of the unbanked Kenyan community, microfinance providers, mobile operators, and the government for implementing effective mobile microfinance.Concerning the unbanked community, the study found that with least awareness efforts and capacity building, those people could turn to more loyal mobile microfinance clients. More than $70 \%$ of the respondents reported to be either self-employed or retailers with low-income. Despite the high connectivity of the investigated sample through mobile phone and their beliefs that mobile microfinance is cheaper and more secured than traditional microfinance, only $1.7 \%$ was highly aware of its availability. While respondents admitted the use of electronic payment on limited situations such as airtime recharge, saving and funds transfer, cash is still the dominated method of payment in Kenya. These results might imply that mobile microfinance could be the best choice for financial inclusions of the remote unbanked Kenya if the mentioned challenges are removed. Furthermore, this is because mobile microfinance could help in improving access to finance through reducing the cost of services, minimizing the physical distance to the access point of the financial providers, and might give a better documentation. Moreover, mobile microfinance might improve microfinance outreach through the opening of untapped markets.Hence, Mobile microfinance intuitions and mobile operators need to exert more efforts in removing the challenges associated with their mobile microfinance services in each concerned. This is done through awareness and mobile microfinance products development. Moreover, the study showed that these efforts might be more fruitful if the microfinance providers and mobile microfinance operators handle them jointly.

Finally, the Kenyan regulators, who have done well in enabling mobile money innovation to develop in the country, may also need to exert additional efforts towards promoting mobile microfinance. These could be done through facilitating healthy competition to achieve more stable microfinance sector and removing barriers to entry such high tariff, bad corporate governance, dispute resolution, and implementation of consumer protection laws to preserve consumers rights and integrity.Since microfinance is very essential for economic growth and financial inclusion, providing effective financial access to the unbanked people in the remote areas in Kenya will give strong support for both the government and the communities.

\section{References}

Angela et al. (2012).Mobile Phone Usage at the Kenyan Base of the Pyramid, Final Report from iHub Research \& Research Solutions Africa.

Black et al. (2002), Modeling consumer choice of distribution channels: an illustration from financial devices, International Journal of Bank Marketing, 20(4), 161-73.http://dx.doi.org/10.1108/02652320210432945

Board of Governor of the Federal Reserve System, Consumers and Mobile Financial Services (2012). 
www.federalreserve.gov/econresdata/consumerresearch_publications.htm.

Casey et al. (2011). Impact of Mobile Money Services on MFI's Operational Costs in Tanzania,Institute for Money, Technology \& Financial Inclusión (IMTFI) www.imtfi.uci.edu/files/presentations/2011/Day\%202/7\%20Conzett.pptx

CGAP (2006). Use of Agents in Branchless Banking for the Poor: Rewards, Risks, and Regulation, https://www.cgap.org/sites/.../CGAP-Focus-Notes-Use-of-Agents-in-Branchless-Bank

Daniel (1999). Provision of Electronic banking in the UK and the republic of Ireland.International',journal of banking marketing, 17(2), 72-82.http://dx.doi.org/10.1108/02652329910258934

Eisenmann, P., \& Alstyne. (2009). Opening Platforms: How, When andWhy? Harvard Business School, Working Paper

FinAccess National Survey (2013). Profiling developments in financial access and usage in Kenya, http://fsdkenya.org/wp-content/uploads/2015/08/13-10-31_FinAccess_2013_Report.pdf

Higgins, K., \& Lyon. (2012). Mobile Money Usage Patterns of Kenyan Small and Medium Enterprises,Innovations: Technology, Governance, Globalization, 7(2), 67-81.

http://www.aboutmicrofinance.com/reaching-the-unbanked-mobile-banking-and-microfinance

Yousif et al. (2011), Best Practices in Mobile Microfinance,

www.imtfi.uci.edu/files/grameen_microfinance_white_paper.pdf

\section{(cc) $\mathrm{BY}$}

This work is licensed under a Creative Commons Attribution 3.0 License. 